\title{
LEG'S COMPARTMENT SYNDROME AFTER RECONSTRUCTION OF THE ANTERIOR CRUCIATE LIGAMENT: CASE REPORT
}

Jorge Sayum Filho', Leonardo Adeo Ramos', Jorge Sayum², Rogério Teixeira de Carvalho', Benno Ejnisman', Marcelo Mitsuro Matsuda', Alexandre Nicolini', Moisés Cohen ${ }^{3}$

\section{ABSTRACT}

The authors report a case of a patient that was submitted to a surgery of reconstruction of anterior cruciate ligament and collateral medial ligament repair of the left knee that complicated to a compartment syndrome.

Keywords - Compartment Syndromes, Anterior Cruciate Ligament; Knee; Postoperative Complications

he had experienced a sprain. The patient was seen by a physician and examined. A knee resonance was requested that resulted in a diagnosis of total rupture of the anterior cruciate ligament and of the medial collateral ligament.

Two weeks later, the patient underwent surgery for reconstruction of the anterior cruciate ligament and repair of the medial collateral ligament.

The surgery lasted for two hours and was performed under rachianesthesia; an infusion pump was used for the arthroscopy, and the graft donor site was the flexor tendons.

Ten hours after surgery, the patient evolved with progressive and intense pain, paresthesia, paresis, with a pallid aspect and tense and shiny skin. A Doppler ultrasound was requested to rule out venous thrombosis; thus measurement of the intracompartmental pressure of the right leg was requested and performed with the Whitesides' apparatus, which verified intracompartmental pressure of $85 \mathrm{mmHg}$.

The patient was immediately referred to the surgical center to perform an urgent decompression fas-

1 - Assistant Physician of the Sports Traumatology Center (CETE) of the Department of Orthopedics and Traumatology (DOT) of Universidade Federal de São Paulo (Unifesp) São Paulo, SP, Brazil

2 - Head of the Department of Orthopedics and Traumatology of Hospital e Maternidade Assunção (HMA) - São Bernardo do Campo, SP, Brazil.

3 - Lecturer of the Department of Orthopedics and Traumatology (DOT) of Universidade Federal de São Paulo (Unifesp) and Head of the Sports Traumatology Center (CETE) - São Paulo, SP, Brazil.

Study conducted at the Sports Traumatology Center (CETE) of the Department of Orthopedics and Traumatology (DOT) of Universidade Federal de São Paulo (Unifesp), São Paulo, SP, Brazil

Mailing address: Rua França Pinto, 186, ap. 61, Vila Mariana - 04016-001 - São Paulo, SP. Email: jorgesayumfilho@hotmail.com Study received for publication: $8 / 20 / 2010$, accepted for publication: $3 / 25 / 2011$.

The authors declare that there was no conflict of interest in conducting this work

This article is available online in Portuguese and English at the websites: www.rbo.org.br and www.scielo.br/rbort 
ciotomy. Two fasciotomies (medial and lateral) were carried out to release the four leg compartments. The patient was discharged from hospital 10 days after surgery. Twenty-one days after surgery, a skin graft was performed by the plastic surgery clinic in the lateral region of the leg, since the only fasciotomy that healed by secondary intention was the medial fasciotomy. Today, two months after surgery, the patient is having physiotherapy, has a sensitivity deficit of the superficial and profound fibular nerve, reduction of range of motion and muscle strength, but manages to walk with a plantigrade foot, and therefore continues under outpatient supervision (Figures 1 and 2).

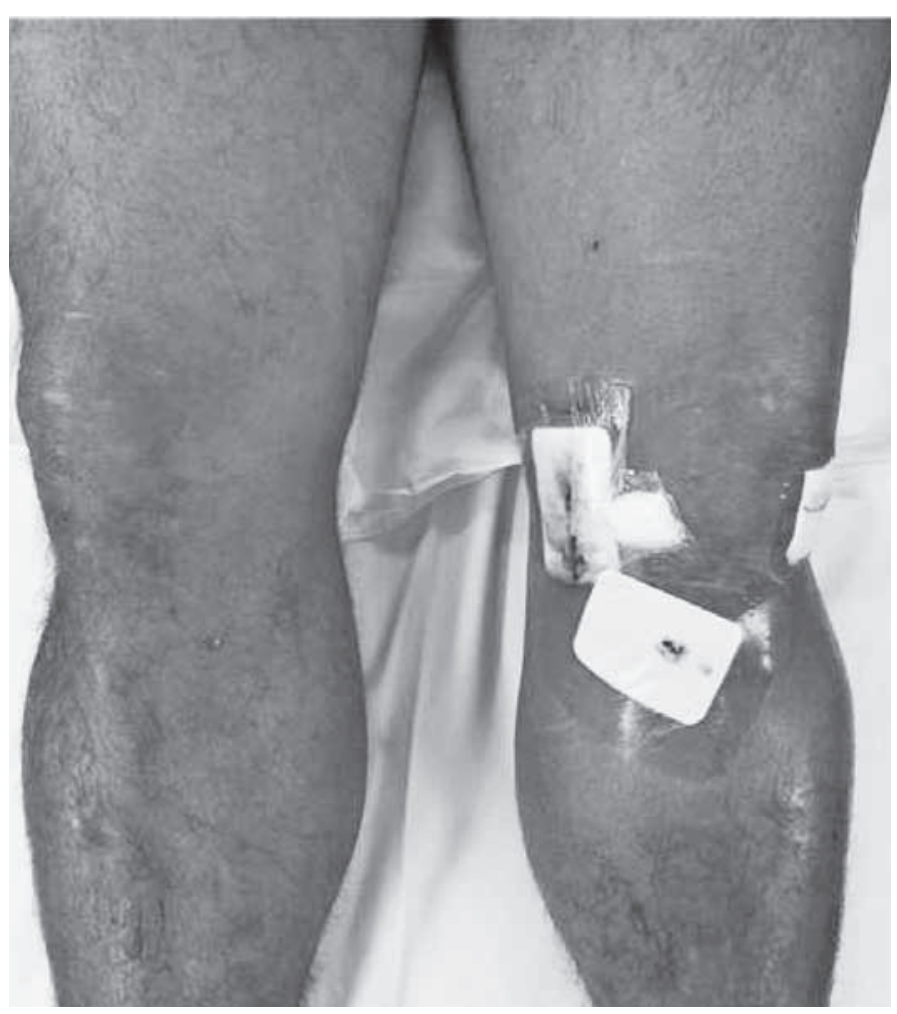

Figure 1 - Left knee in the immediate postoperative period.

\section{DISCUSSION}

Anatomical compartments are very limited spaces existing in the musculoskeletal system, whose walls are formed by bones and by osteofascial structures, which are relatively inelastic elements. The compartment syndrome develops when there is a pressure increase in the compartment space, which impairs tissue perfusion and jeopardizes the viability of the structures existing there (muscles, tendons, vessels and nerves $)^{(1,2)}$.

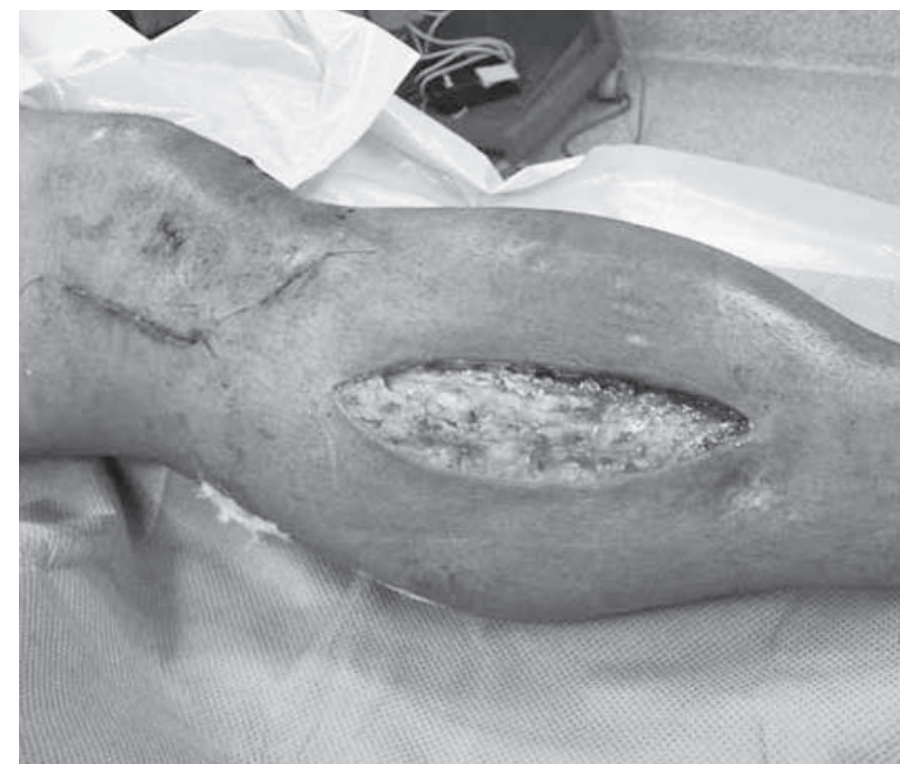

Figure 2 - Medial fasciotomy.

The intracompartmental pressure can be increased on account of internal or external causes and can reach levels above $100 \mathrm{mmHg}$. The degree of injury will depend on the speed at which the pressure increase is established and its duration. The pathogenesis is explained by the increase of intracompartmental pressure at sufficient levels to impair tissue microcirculation, while the final substratum is represented by interstitial and intracellular edema. There is a buildup of fluids and of intracompartmental pressure that leads to acute ischemia, which in turn leads to an increase in capillary permeability, which increases the interstitial edema, thus producing the installation of a vicious cycle that if maintained, leads to the complete destruction of the musculature, vessels and nerves ${ }^{(2-4)}$.

If many compartments are affected the crush syndrome develops with renal failure, shock and even death. A varied spectrum of lesions of the soft parts, bones and vessels can trigger a compartment syndrome $^{(3,5)}$.

The clinical profile consists of: increase of intracompartmental pressure, progressive pain in the compartment, paresthesia, paresis and dark coloration of the skin in the distal region.

The most important differential diagnoses are obstructive or semi-obstructive arterial disorders that, leading to ischemia, can cause similar complaints ${ }^{(5-7)}$.

Acute compartment syndrome has only one form of treatment: urgent decompression fasciotomy, which will allow the expansion of tissues, the normalization of pressure, and consequently, reperfusion ${ }^{(6,7)}$. 
On account of the foregoing, we presented the case of a patient submitted to anterior ligament reconstruction (arthroscopic route) and repair of the medial collateral ligament of the right knee, who was treated according to orthopedic literature. It is a rare case and

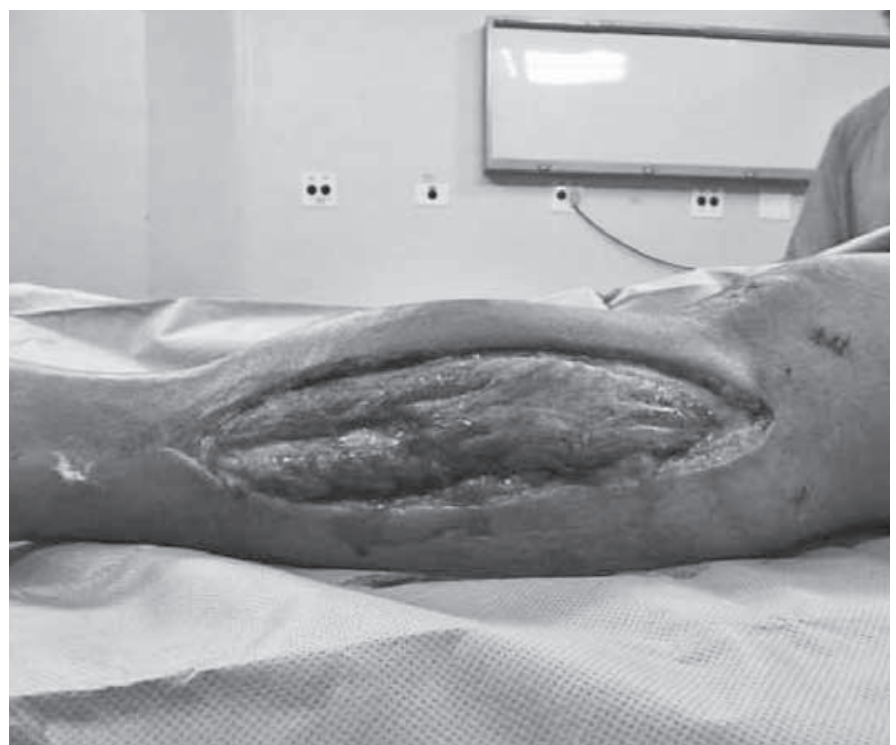

Figure 3 - Lateral fasciotomy. seldom reported in literature, since surgeons are generally unwilling to publish their complications. But it is a good idea to stress that the compartment syndrome exists and every medical surgeon should know how to diagnose and treat it (Figures 3 and 4).

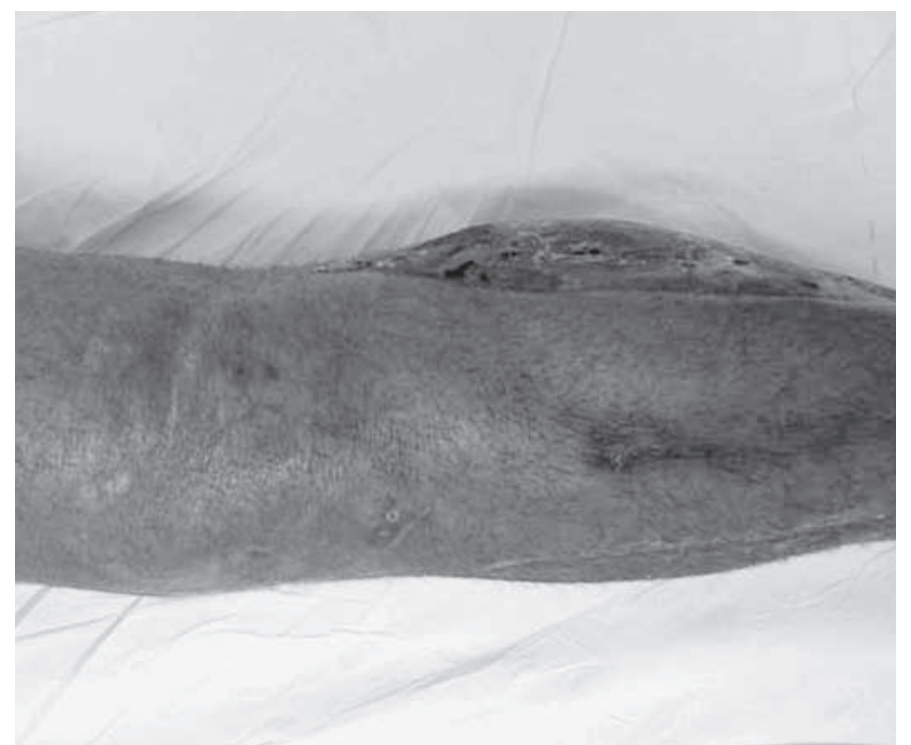

Figure 4 - Twenty-one days after surgery. Note that there is closing by secondary intention only of the medial fasciotomy and the need for a skin graft in the lateral fasciotomy.

\section{REFERENCES}

1. Clarke HD. Anatomy.. In; Scott WN. Insall \& Scott surgery of the knee. 4th ed. New York: Churchill Livingstone; 2006. p. 3-67.

2. Edwards PD, Miles KA, Owens SJ, Kemp PM, Jenner JR. A new non invasive test for the detection of compartment syndromes. Nucl Med Commun. 1999;20(3):215-8.

3. Hallock GG. An endoscopic technique for descompressive fasciotomy. Ann Plast Surg. 1999;43(6):668-70.

4. Tollens $T$, Janzing $H$, Broos $P$. The pathophysiology of the acute compartment syndrome. Acta Chir Belg. 1998;98(4):171-5.
5. Whitesides TE, Haney TC, Morimoto K, Harada H. Tissue pressure measurements as a determinant for the need of fasciotomy. Clin Orthop Relat Res. 1975;(113):43-51.

6. Turnbull D, Mills GH. Compartment syndrome associated with the Lloyd Davies position. Three case reports and review of the literature. Anaesthesia. 2001;56(10):980-7.

7. Hughston JC. Complications of anterior cruciate ligament surgery. Orthop Clin North Am. 1985;16(2):237-40. 